\title{
Pengaruh Chemcrete Modifier Terhadap Nilai Stabilitas dan Flow pada Campuran Hot Rooled Sheet
}

\author{
Ami Asparini \\ Staf Pengajar Program Studi Diploma Teknik Sipil FTSP ITS
}

\begin{abstract}
ABSTRAK
Kondisi Jalan Pantura Jalur Gersik- Lamongan dengan pelapisan permukaan memakai HRS (Hot Rolled Sheet) mengalami percepatan kerusakan pada permukaan perkerasan yang ada. Hal ini akibat adanya volume lalulintas yang cukup padat dan beban kendaraan yang berat (berlebihan). Sedangkan kerusakan yang terjadi umumnya berupa: Rutting/ alur akibat beban ekstra berat, Corrugation/ keriting akibat gaya rem, teroksidasi sinar matahari, bleeding akibat panas matahari, serta shoving akibat gaya centrifugal yang ada. Adanya permasalahan diatas memotivasi penulis untuk dilakukannya penelitian HRS dengan Chemcrete Modifier sebagai bahan tambahan aspal, sejauh mana perilakunya terhadap stabilitas dan flow, selanjutnya diharapkan dapat mengatasi masalah yang ada. Metode penelitian yang dilakukan dengan mengacu rujukan AASHTO, ASTM, dan BS 812, yaitu dengan menganalisa fisik material HRS dilaboratorium (Berat jenis dan Penyerapan, Keausan, Soundness test, Analisa pembagian butir gradasi, Kadar organik agregat halus, Kelekatan agregat terhadap aspal. Selain itu juga dilakukan test Aspal (penetrasi, titik lembek, titik bakar, daktilitas). Selanjutnya perencanaan komposisi agregat campuran HRS, dengan variasi kadar aspal 5,5\% sampai dengan 7,5\% dilakukan Test Marshall I dicapai kadar aspal optimum. Berdasarkan kadar aspal optimum dilakukan Test Marshall II untuk HRS dan HRS + chemcrete dengan variasi umur 1 hari, 14 hari, 28 hari, 2 bulan untuk dievaluasi perilakunya. Dari hasil penelitian laboratorium didapat HRS kelas B (beban lalu lintas sedang s/ d berat) dengan 2 x 75 pukulan menghasilkan stabilitas dan flow lebih tinggi dari standart (test marshall I ) dengan kadar aspal optimum 6,9\% dan variasi umur 1 hari, 14 hari, 28 hari dan 2 bulan pada Test Marshall II didapat campuran HRS + Chemcrete nilai stabilitas meningkat dan flow dalam batas toleransi, secara teknis memenuhi syarat. J adi Chemcrete bisa dipertanggungjawabkan dimana kekokohan aspalnya juga meningkat, sehingga dapat memperpanjang umur pelayanan perkerasan yang ada.
\end{abstract}

Kata kunci : Hot Rolled Sheet (HRS), Chemcrete Modifier

\section{PENDAHULUAN}

Kondisi Jalan Pantura Jalur GersikLamongan dengan pelapisan permukaan HRS (Hot Rolled Sheet) mengalami percepat kerusakan pada permukaan perkerasan yang ada. Hal ini akibat adanya volume lalu lintas yang cukup padat dan beban kendaraan yang ekstra berat (berlebihan). Sedangkan kerusakan yang terjadi umumnya berupa : Rutting/alur akibat beban ekstra berat, Corrugation akibat gaya rem, Teroksidasi sinar matahari, serta Bleeding akibat panas matahari, dan Shoving akibat gaya centrifugal [1]. Untuk mengatasi masalah tersebut diatas akan dicoba menambahkan media Chemcrete Modifier pada campuran HRS, sehingga dapat diketahui sejauh mana pengaruh perilaku
HRS dengan tambahan Chemcrete tersebut, terutama stabilitas dan flownya, sehingga hasilnya dapat dipakai sebagai spesifikasi teknik bagi HRS itu sendiri.

\section{TINJ AUAN PUSTAKA}

\subsection{Tinjauan pemakaian HRS (Hot Rolled Sheet)}

HRS adalah campuran agregat yang bergradasi senjang/timpang (Gap Grade) yang dicampur secara panas dan dipadatkan pada suhu tertentu dan merupakan pengetrapan pelapisan perkerasan pada permukaan atas (lapisan tipis aspal beton) [2]. Ada dua jenis HRS yaitu : 
HRS Kelas A : untuk jalan dengan beban Ialu lintas ringan sampai dengan sedang dan berkarakteristik keawetan, fleksibilitas, daya tahan terhadap fatique (kelelahan), sedangkan

HRS Kelas B : untuk jalan dengan beban Ialu lintas sedang sampai berat dengan karakteristik yang utama stabilitas selain fleksibilitas dan daya tahan terhadap fatique (kelelahan) serta relatif tipis bila dibanding lapisan AC (Aspal Beton) $\pm 2,5-3 \mathrm{~cm}$ padat, tetapi juga masih kaku [3].

Bahan campuran HRS terdiri dari Agregat kasar (coarse aggregate), agregat halus (fine aggregate), bahan pengisi (filler) dan aspal AC dengan komposisi tertentu. Persentase Agregat Kasar Kelas A 20 - 40 \% untuk HRS kelas B (30 - $50 \%$ ) sebagian besar campuran diisi agregat halus dan filler. Disini Stabilitas campuran sebagian besar ditentukan oleh campuran mortar (Agregat halus + filler + aspal). Sehingga dengan keadaan yang demikian diperoleh suatu campuran yang tahan terhadap perubahan bentuk (deformasi) akibat beban lalu lintas yang berulang - ulang. Sehingga dari kondisi diatas dapat dikatakan HRS mempunyai beberapa kelebihan sebagai berikut :

\section{- Fleksibilitas yang tinggi}

Yaitu kemampuan struktur perkerasan untuk mengikuti perubahan bentuk (lentur) tanpa retak akibat beban lalu lintas. Adanya campuran agregat mortar didominasi agregat halus memiliki kelenturan yang tinggi dalam mengikuti perubahan bentuk lapisan perkerasan

\section{- Durabilitas}

Mempunyai keawetan (daya tahan terhadap cuaca) yaitu mempunyai kemampuan menyerap aspal lebih banyak, sehingga dapat menyelimuti partikel lebih tebal, ruang pori dalam campuran lebih kecil, yang akhirnya sulit ditembus air (pengaruh kadar pori campuran) atau Air Void Content, sehingga memperawet perkerasan yang ada.

\section{- Fatique}

Adalah suatu kemampuan menahan retak akibat beban berulang karena kelelahan (flow)
Adalah kemudahan campuran untuk dikerjakan pada saat pencampuran, penghamparan maupun pemadatan dilapangan. Hal ini dipengaruhi oleh gradasi agregat dan bentuk butir HRS bergradasi senjang dengan kompunen agregat halus, filler dan aspal, dimana agregat kasarnya memberikan perlawanan kecil pada waktu pemadatan oleh karena itu lebih mudah dipadatkan.

\section{- $\quad$ Skid Resistan}

HRS mempunyai Skid Resistan yang cukup aman artinya mempunyai permukaan kaku \& yang tidak licin, sehingga mempunyai hambatan yang cukup besar pada gesekan dan aman untuk pergerakan lalu lintas kendaraan.

\subsection{Chemcrete Modifier}

Chemcrete Modifier adalah cairan yang mengandung katalis dan terdapat dalam bentuk Iarutan minyak [4]. Apabila bahan ini ditambahkan pada aspal yang digunakan pada konstruksi lapis perkerasan, maka didalam aspal tersebut akan terjadi Reaksi Polymer sedemikian rupa sehingga perkerasan aspal yang bersangkutan khususnya bagian yang aspal akan menjadi kokoh. Yang dimaksud kokoh adalah :

- Stabilitas lebih tinggi dan flow masih dalam toleransi (dari standar teknis yang ada).

- Ketahanan terhadap proses oksidasi meningkat.

- Kelekatan lebih baik sehingga tahan terhadap stripping.

- Tidak peka terhadap perubahan temperatur, sehingga mempunyai umur pelayanan lebih Iama.

Tulisan diatas didasarkan pada penelitian yang dilakukan oleh Darmanto, Surisman, Ami Asparini 1989, Studi Perbandingan HRS dan HRS memakai Chemcrete ditinjau dari nilai Stabilitas dan flow sebagai lapis permukaan jalan Gresik - Lamongan KM Sby 16+350 - 17+350, Tugas Akhir LPPU FTSP ITS [4].

- Workability 


\section{METODOLOGI PENELITIAN}

Metodologi penelitian yang dilakukan dalam penelitian ini sesuai persyaratan teknis MPBJ (Manual Pemeriksaan Bahan Jalan) tahun 1976 [5], dengan rujukan AASHTO, ASTM dan BS 812 sebagai berikut :

- Pemeriksaan fisik material HRS dilaboratorium meliputi : berat jenis dan absorsi, keausan, soundness test, analisa pembagian butir gradasi agregat, kadar organik agregat halus, kelekatan agregat terhadap aspal, test aspal (penentrasi, titik lembek, titik bakar, daktilitas)

- Perencanaan komposisi agregat campuran HRS (agregat + filler + aspal) dan benda uj i ditest Marshall I didapat kadar aspal optimum.

- Perencanaan campuran HRS dan HRS + Chemcrete dengan kadar aspal optimum dan variasi umur 1 hari, 14 hari, 28 hari, 2 bulan dilakukan test Marshall II sehingga didapat nilai stabilitas dan flow masing - masing, sejauh mana perilakunya secara teknis.

- Evaluasi dan Kesimpulan

\section{PEMERIKSAAN LABORATORIUM BAHAN CAMPURAN HRS}

\subsection{Pemeriksaan Fisik Agregat, Filler dan Aspal AC 60/70}

Dalam suatu campuran HRS, jumlah agregat yang digunakan \pm 85 - $90 \%$ dari berat campurannya, sehingga fisik agregat akan berpengaruh terhadap perilaku HRS. Untuk memperoleh suatu perkerasan yang memenuhi persyaratan Manual Pemeriksaan Bahan Jalan [2] di perlukan agregat yang memenuhi persyaratan dalam tabel 1 . Agregat kasar (batu pecah), Agregat sedang (batu pecah), Agregat halus (pasir alam), Filler kapur.
Tabel 1.Pemeriksaan Fisik Agregat dan Filler.

\begin{tabular}{|c|c|c|c|c|c|c|}
\hline \multirow[b]{2}{*}{ Jenis test } & \multicolumn{4}{|c|}{ Hasil pemeriksaan } & \multirow[t]{2}{*}{ Standar } & \multirow{2}{*}{$\begin{array}{c}\text { Keteran } \\
\text { gan }\end{array}$} \\
\hline & F1 & $\mathrm{F} 2$ & $\mathrm{~F} 3$ & filler & & \\
\hline Bulle Specific grafity & 2.52 & 2.62 & 2.61 & 2.61 & $2.4-2.8$ & $\begin{array}{l}\text { Meme } \\
\text { nuhi }\end{array}$ \\
\hline Apperend Specific & 2.70 & 2.76 & 2.76 & 2.76 & Min 2.5 & $\begin{array}{l}\text { Meme } \\
\text { nuhi }\end{array}$ \\
\hline Absortion & $\begin{array}{l}27.1 \\
8\end{array}$ & $\begin{array}{l}28.4 \\
0\end{array}$ & - & - & $\begin{array}{l}\text { Max } \\
40 \%\end{array}$ & $\begin{array}{l}\text { Memen } \\
\text { uhi }\end{array}$ \\
\hline $\begin{array}{l}\text { Test Keausan/Los } \\
\text { Angeles }\end{array}$ & 2.78 & 2.08 & 2.08 & 2.08 & $\begin{array}{l}\operatorname{Max} 3 \\
\%\end{array}$ & $\begin{array}{l}\begin{array}{l}\text { Meme } \\
\text { nuhi }\end{array} \\
\end{array}$ \\
\hline Soundness/Pelapukan & & $\begin{array}{l}95.4 \\
0\end{array}$ & $\begin{array}{l}96.9 \\
0\end{array}$ & $\begin{array}{l}96.9 \\
0\end{array}$ & $\begin{array}{l}\text { Min } 50 \\
\%\end{array}$ & $\begin{array}{l}\text { Meme } \\
\text { nuhi }\end{array}$ \\
\hline $\begin{array}{l}\text { Analisa Saringan : } \\
\text { - Agregat Kasar F1 } \\
\text { - Agregat Sedang F2 } \\
\text { - Agregat Halus F3 }\end{array}$ & 30 & $\begin{array}{l}- \\
25\end{array}$ & $\begin{array}{l}- \\
\overline{45}\end{array}$ & : & $30-50$ & $\begin{array}{l}\text { Meme } \\
\text { nuhi }\end{array}$ \\
\hline $\begin{array}{l}\text { Test Kelekatan } \\
\text { terhadap aspal }\end{array}$ & $99 \%$ & - & & - & $\begin{array}{l}\text { Min } 95 \\
\%\end{array}$ & $\begin{array}{l}\begin{array}{l}\text { Meme } \\
\text { nuhi }\end{array} \\
\text {. }\end{array}$ \\
\hline $\begin{array}{l}\text { Sand Equivalent } \\
\text { /Kebersihan }\end{array}$ & - & - & $\begin{array}{l}\text { Warna } \\
\text { Kunig } \\
\text { Muda } \\
\text { No. 2 }\end{array}$ & - & $\begin{array}{l}\text { Diatas } \\
\text { Warna } \\
\text { Standart }\end{array}$ & $\begin{array}{l}\text { Meme } \\
\text { nuhi }\end{array}$ \\
\hline
\end{tabular}

Dari hasil pemeriksaan Aspal AC 60/70 diperoleh hasil seperti disajikan pada Tabel 2.

Tabel 2. Hasil Test Aspal AC 60/70

\begin{tabular}{|c|c|c|c|c|}
\hline \multirow{2}{*}{ Jenis Test } & \multirow{2}{*}{ Hasil Test } & \multicolumn{2}{|c|}{ Standart } & \multirow{2}{*}{ Keterangan } \\
\hline & & Min & Max & \\
\hline Penetrasi & $64,80 \mathrm{~mm}$ & $60 \mathrm{~mm}$ & $79 \mathrm{~mm}$ & $\begin{array}{l}\text { Memenuhi } \\
\text { Persyaratan }\end{array}$ \\
\hline Titik nyala\&bakar & $\begin{array}{l}312.5- \\
321^{\circ} \mathrm{C}\end{array}$ & $200^{\circ} \mathrm{C}$ & - & $\begin{array}{l}\text { Memenuhi } \\
\text { Persyaratan }\end{array}$ \\
\hline Titik lembek & $49,77^{\circ} \mathrm{C}$ & $48^{\circ} \mathrm{C}$ & $58^{\circ} \mathrm{C}$ & $\begin{array}{l}\text { Memenuhi } \\
\text { Persyaratan }\end{array}$ \\
\hline Daktilitas & $125,95 \mathrm{~cm}$ & $100 \mathrm{~cm}$ & - & $\begin{array}{l}\text { Memenuhi } \\
\text { Persyaratan }\end{array}$ \\
\hline Berat jenis & 1,03 & 1.00 & - & $\begin{array}{l}\text { Memenuhi } \\
\text { Persyaratan }\end{array}$ \\
\hline
\end{tabular}

\subsection{Komposisi Agregat Campuran HRS}

Dari hasil analisa saringan campuran HRS, Agregat Kasar (F1), Agregat Sedang (F2), Agregat Halus (F3) pasir alam dan filler diperoleh komposisi yang memenuhi syarat gradasi, seperti terlihat pada Tabel 3, dan disajikan dalam bentuk grafik pada gambar 1.

Tabel 3. Komposisi Agregat Campuran HRS

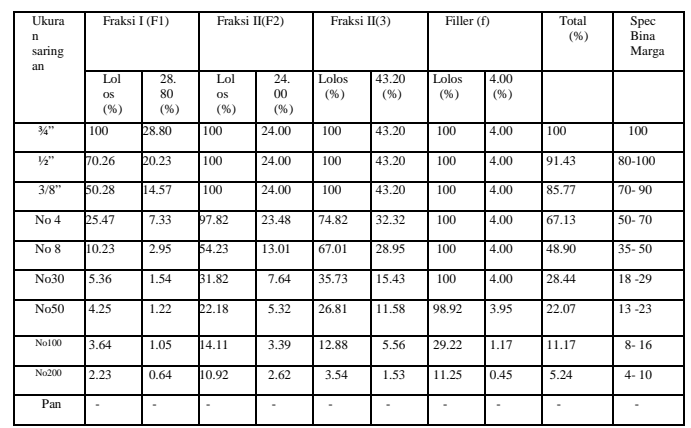




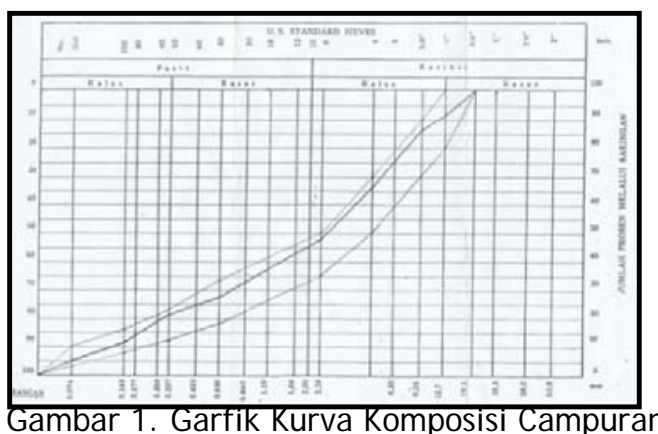

Agregat HRS

\subsection{Perencanaan Komposisi Campuran HRS}

Komposisi Campuran Agregat + Filler + Aspal untuk Test Marshall I dengan langkah langkah sebagai berikut :

- Benda uji dipadatkan dengan memadatkan Campuran HRS.

- Kadar Aspal yaitu : 5,5\% 6 \% 6,5\% $7 \%$ dan $7,5 \%$

- Pemadatan dilakukan 2 x 75 pukulan.

Tabel 4. Perencanaan Campuran dan Variasi Aspal (Agregat + Filler + Aspal)

\begin{tabular}{|c|c|c|c|c|c|c|c|c|c|c|}
\hline $\begin{array}{c}\% \\
\text { Aspal } \\
\end{array}$ & \multicolumn{2}{|c|}{5.50} & \multicolumn{2}{|c|}{6.00} & \multicolumn{2}{|c|}{6.50} & \multicolumn{2}{|c|}{7.00} & \multicolumn{2}{|c|}{7.50} \\
\hline Mater & & erat & & erat & & erat & & erat & & \\
\hline ial & $\%$ & $\begin{array}{ll}g r \\
\end{array}$ & $\%$ & $\mathrm{gr}$ & $\%$ & $\mathrm{gr}$ & $\%$ & Gr & $\%$ & Gr \\
\hline F1 & 7.32 & 326.59 & 1.07 & 324.86 & 6.93 & 323.14 & 26.78 & 321.41 & 22.64 & 319.68 \\
\hline F2 & 22.68 & 272.16 & 22.56 & 270.72 & 22.44 & 269.28 & 22.32 & 267.84 & 22.20 & 266.40 \\
\hline F3 & 40.82 & 489.89 & 40.61 & 487.30 & 40.39 & 484.70 & \begin{tabular}{|l|l}
40.18 \\
\end{tabular} & (482.11 & 39.96 & 479.00 \\
\hline Filler & 3.78 & 455.36 & \begin{tabular}{|l}
3.76 \\
\end{tabular} & 45.12 & \begin{tabular}{|l|l}
3.74 \\
\end{tabular} & \begin{tabular}{|l|l|} 
\\
\end{tabular} & \begin{tabular}{|l|l}
3.72 \\
\end{tabular} & 444.64 & 3.70 & 44.40 \\
\hline Aspal & 5.50 & $\overline{66.00}$ & 6.00 & 72.00 & \begin{tabular}{|l|l}
6.50 \\
\end{tabular} & 778.00 & 7.00 & 84.00 & 7.50 & 90.00 \\
\hline Iotal & \begin{tabular}{|l|l|}
100 \\
\end{tabular} & 1200 & 100 & 1200 & 100 & $\mid 1200$ & 100 & 11200 & 100 & 1200 \\
\hline
\end{tabular}

Dari hasil perencaaan diperoleh komposisi campuran Agregat + Filler + Aspal untuk Marshall Test I (tabel 4). Hasil Test Marshall laboratorium dan grafik masing - masing parameter sehingga diperoleh kondisi kadar aspal optimum. Hasil test Marshall I tersaji pada Tabel 5.
Tabel 5. Hasil Test Marshall I

\begin{tabular}{|c|c|c|c|c|c|}
\hline $\begin{array}{l}\text { Kadar } \\
\text { Aspal }\end{array}$ & Kode & $\begin{array}{c}\text { Stability } \\
(\mathrm{kg})\end{array}$ & $\begin{array}{l}\text { Flow } \\
(\mathrm{mm})\end{array}$ & $\begin{array}{c}\text { Marshall } \\
\text { Quotient } \\
(\mathrm{t} / \mathrm{mm})\end{array}$ & $\begin{array}{c}\text { Air } \\
\text { Voids } \\
\text { (\%) }\end{array}$ \\
\hline \multirow{4}{*}{$5,5 \%$} & $\mathrm{I}$ & 610,80 & 2,31 & 2,59 & 9,01 \\
\hline & II & 620,20 & 2,39 & 2,54 & 7,79 \\
\hline & II & 636,40 & 2,52 & 2,47 & 6,56 \\
\hline & $\begin{array}{c}\text { Rata- } \\
\text { rata }\end{array}$ & 622,50 & 2,40 & 2,53 & 7,78 \\
\hline \multirow{4}{*}{$6,5 \%$} & I & 680,20 & 2,68 & 2,49 & 5,78 \\
\hline & II & 710,40 & 2,73 & 2,55 & 6,64 \\
\hline & II & 605,30 & 2,77 & 2,14 & 6,19 \\
\hline & $\begin{array}{c}\text { Rata- } \\
\text { rata }\end{array}$ & 665,30 & 2,72 & 2,40 & 6,21 \\
\hline \multirow{4}{*}{$6,5 \%$} & I & 660,30 & 3,11 & 2,08 & 5,82 \\
\hline & II & 730,20 & 3,43 & 2,09 & 5,00 \\
\hline & II & 743,60 & 3,55 & 2,05 & 5,41 \\
\hline & Rata-rata & 711,40 & 3,36 & 2,07 & 5,41 \\
\hline \multirow{4}{*}{$7,0 \%$} & $\mathrm{I}$ & 736,60 & 3,81 & 1,89 & 5,02 \\
\hline & II & 716,20 & 3,79 & 1,85 & 4,18 \\
\hline & II & 852,50 & 3,96 & 2,11 & 3,76 \\
\hline & Rata-rata & 768,40 & 3,85 & 1,96 & 4,30 \\
\hline \multirow{4}{*}{$7,5 \%$} & $\mathrm{I}$ & 788,20 & 4,42 & 1,75 & 3,80 \\
\hline & II & 872,00 & 4,59 & 1,86 & 4,22 \\
\hline & II & 860,30 & 4,36 & 1,93 & 3,37 \\
\hline & Rata-rata & 840,10 & 4,46 & 1,85 & 3,80 \\
\hline
\end{tabular}

Dari hasil pemeriksaan test Marshall I (laboratorium) dapat diketahui dengan variasi kadar aspal 5,5\% $6 \%$ 6, $5 \% 7 \%$ dan $7,5 \%$ dari masing - masing 3 benda uji didapat hasil sebagai berikut :

- Stabilitas berkisar antara 622,5 $840,1 \mathrm{~kg}$ dengan syarat $>550 \mathrm{~kg}$ (ok)

- Nilai Flow berkisar antara 2,4 - 4,46 $\mathrm{mm}$ dengan syarat $2-4,5 \mathrm{~mm}$ (ok)

- $\quad$ Air Void Content berkisar 7,78 - 3,8 $\%$ dengan syarat 3 - $5 \%$ untuk kadar aspal 6,6 s/d 7,5\%(ok)

- Marshall Quotient cukup baik berkisar $1,85-2,53 \mathrm{KN} / \mathrm{mm}$

Persyaratan Spesifikasi Campuran pada test Marshall dapat dilihat pada tabel 6 [6] sebagai berikut :

Tabel 6. Spesifikasi Campuran pada test Marshall

\begin{tabular}{|l|c|c|}
\hline \multirow{2}{*}{ Sifat Campuran } & \multicolumn{2}{|c|}{ Batas Sifat HRS } \\
\cline { 2 - 3 } & HRS kelas A & HRS kelas B \\
\hline - Kadar Pori Udara & $3-5 \%$ & $3-5 \%$ \\
- Ketebalan film bitumen & 8 micron & 8 micron \\
- Marshall Quotient & $1-3 \mathrm{KN} / \mathrm{mm}$ & $1,8-4 \mathrm{KN} / \mathrm{mm}$ \\
- Stabilitas Marshall & $450-850 \mathrm{~kg}$ & $>550-1250 \mathrm{~kg}$ \\
\hline
\end{tabular}


Grafik hasil test Stabilitas aspal tersaj i pada Gambar 2.

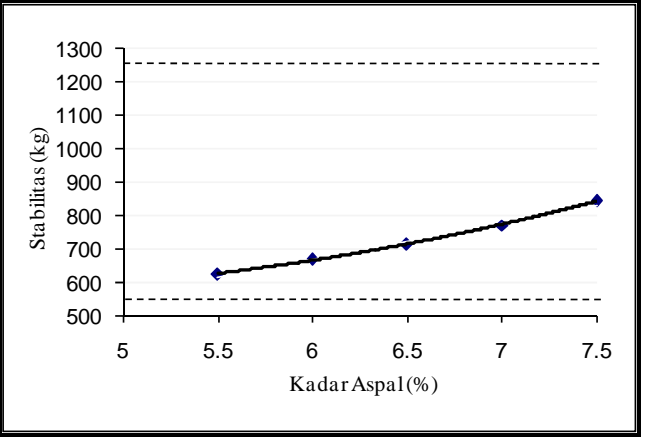

Gambar 2. Grafik Stabilitas

Grafik hasil test Flow aspal tersaji pada Gambar 3.

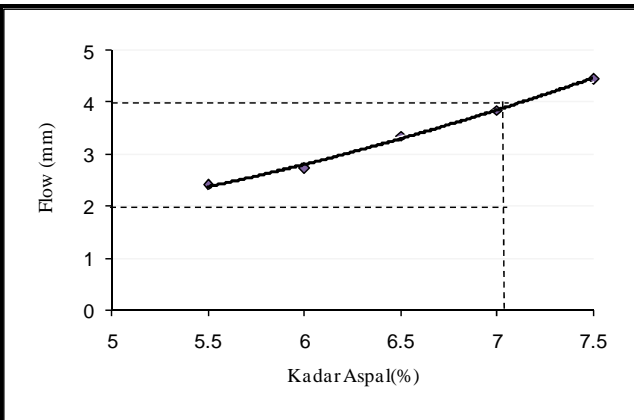

Gambar 3. Grafik Flow

Grafik hasil test Air Voids Content aspal tersaji pada Gambar 4.

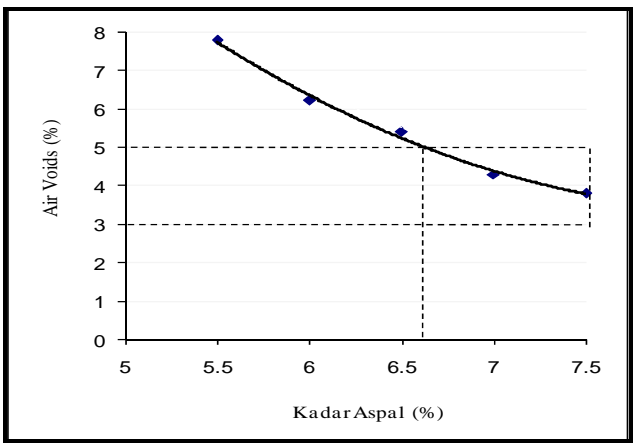

Gambar 4. Grafik Air Voids Content
Grafik hasil test Quotient Marshall aspal tersaj i pada Gambar 5.

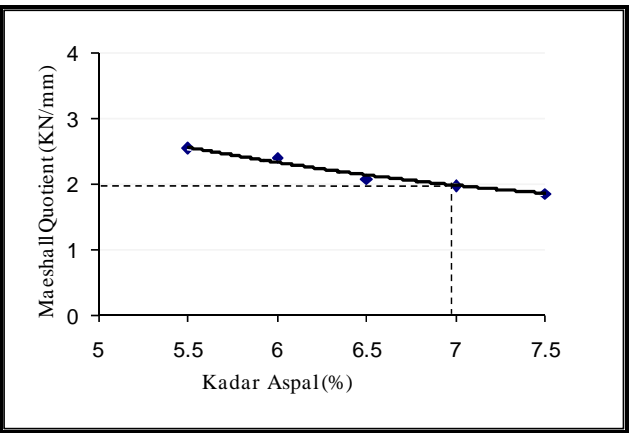

Gambar 5. Grafik Quotient Marshall

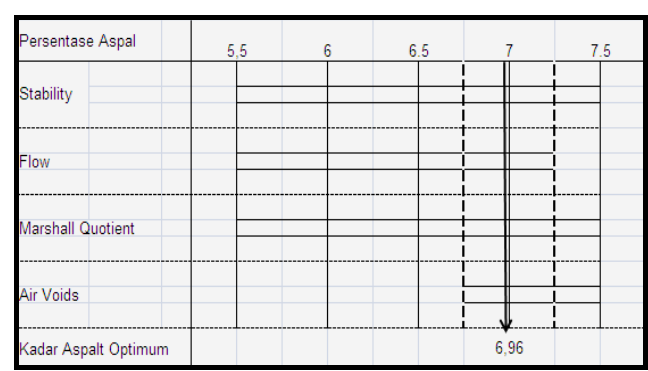

Gambar 6. Kadar Aspal Optimum

Dari grafik 6 diperoleh Kadar Aspal Optimum Aspal $=\frac{6,70+7,22}{2}=6,96 \%$

\section{PERENCANAAN CAMPURAN HRS OPTIMUM}

Kadar aspal optimum dicapai pada saat kadar aspal 6,96 \% pada campuran HRS dan HRS + Chemcrete dengan komposisi campuran chemcrete sebesar $4 \%$ berat aspal dengan variasi umur 1 hari, 14 hari, 28 hari dan 2 bulan diperoleh parameter parameter seperti terlihat pada Tabel 7 dan Tabel 8. 
Tabel 7 : Hasil Test Marshall II campuran HRS

\begin{tabular}{|c|c|c|c|c|c|}
\hline Umur & $\begin{array}{l}\text { Bitumen } \\
\text { Content }\end{array}$ & $\begin{array}{l}\text { Max Sp } \\
\text { Combi- } \\
\text { nedMix }\end{array}$ & $\begin{array}{l}\text { Flow } \\
(\mathrm{mm})\end{array}$ & $\begin{array}{c}\text { Stabi- } \\
\text { lity } \\
(\mathrm{kg})\end{array}$ & $\begin{array}{l}\text { Marshal } \\
\text { Quotient } \\
\text { (KN/mm) }\end{array}$ \\
\hline \multirow{3}{*}{1 hari } & \multirow{3}{*}{6,96} & \multirow{3}{*}{ 2,39 } & 2.50 & 480 & \multirow{3}{*}{1,90} \\
\hline & & & 2.50 & 463 & \\
\hline & & & 2.35 & 482 & \\
\hline $\begin{array}{l}\text { Rata- } \\
\text { rata }\end{array}$ & & & 2,45 & 475 & \\
\hline \multirow{3}{*}{$\begin{array}{l}14 \\
\text { hari }\end{array}$} & \multirow{3}{*}{6,96} & \multirow{3}{*}{2,39} & 3.00 & 743 & \multirow{3}{*}{2,46} \\
\hline & & & 2.40 & 623 & \\
\hline & & & 3,00 & 748 & \\
\hline $\begin{array}{l}\text { Rata- } \\
\text { rata }\end{array}$ & & & 2,80 & 704 & \\
\hline \multirow{3}{*}{$\begin{array}{l}28 \\
\text { hari }\end{array}$} & \multirow{3}{*}{ 6,96 } & \multirow{3}{*}{ 2,39 } & 3.05 & 792 & \multirow{3}{*}{2.48} \\
\hline & & & 3.30 & 765 & \\
\hline & & & 3.05 & 684 & \\
\hline $\begin{array}{l}\text { Rata- } \\
\text { rata }\end{array}$ & & & 3.13 & 797 & \\
\hline \multirow{3}{*}{$\begin{array}{l}60 \\
\text { hari }\end{array}$} & \multirow{3}{*}{6.96} & \multirow{3}{*}{ 2,39 } & 3.07 & 799 & \multirow{3}{*}{2.54} \\
\hline & & & 3.30 & 852 & \\
\hline & & & 3.08 & 805 & \\
\hline $\begin{array}{l}\text { Rata- } \\
\text { rata }\end{array}$ & & & 3.15 & 819 & \\
\hline
\end{tabular}

Tabel 8 : Hasil Test Marshall II campuran HRS+ Chemcrete

\begin{tabular}{|c|c|c|c|c|c|}
\hline Umur & $\begin{array}{l}\text { Bitu- } \\
\text { men } \\
\text { Content }\end{array}$ & $\begin{array}{l}\text { Max Sp } \\
\text { Combi- } \\
\text { nedMix }\end{array}$ & $\begin{array}{l}\text { Flow } \\
(\mathrm{mm})\end{array}$ & $\begin{array}{l}\text { Stabi- } \\
\text { lity } \\
(\mathrm{kg})\end{array}$ & $\begin{array}{l}\text { Marshal } \\
\text { Quotient } \\
(\mathrm{KN} / \mathrm{mm})\end{array}$ \\
\hline \multirow{3}{*}{$\begin{array}{l}1 \\
\text { hari }\end{array}$} & \multirow{3}{*}{6,96} & \multirow{3}{*}{ 2,39 } & 2.30 & 559 & \multirow{3}{*}{2.49} \\
\hline & & & 2.30 & 655 & \\
\hline & & & 2.60 & 616 & \\
\hline $\begin{array}{l}\text { Rata- } \\
\text { rata }\end{array}$ & & & 2,40 & 610 & \\
\hline \multirow{3}{*}{$\begin{array}{l}\text { 14ha } \\
\text { ri }\end{array}$} & \multirow{3}{*}{6,96} & \multirow{3}{*}{2,39} & 2.80 & 830 & \multirow{3}{*}{ 2,96 } \\
\hline & & & 2.80 & 845 & \\
\hline & & & 2.80 & 862 & \\
\hline $\begin{array}{l}\text { Rata- } \\
\text { rata }\end{array}$ & & & 2,80 & 846 & \\
\hline \multirow{3}{*}{$\begin{array}{l}28 \\
\text { hari }\end{array}$} & \multirow{3}{*}{6,96} & \multirow{3}{*}{2,39} & 3.05 & 999 & \multirow{3}{*}{3.00} \\
\hline & & & 3.30 & 977 & \\
\hline & & & 3.30 & 982 & \\
\hline $\begin{array}{l}\text { Rata- } \\
\text { rata }\end{array}$ & & & 3.22 & 986 & \\
\hline \multirow{3}{*}{$\begin{array}{l}\text { 60ha } \\
\text { ri }\end{array}$} & \multirow{3}{*}{6.96} & \multirow{3}{*}{2,39} & 3.30 & 1039 & 3.03 \\
\hline & & & 3.30 & 1051 & \\
\hline & & & 3.56 & 1057 & \\
\hline $\begin{array}{l}\text { Rata- } \\
\text { rata }\end{array}$ & & & 3.39 & 1049 & \\
\hline
\end{tabular}

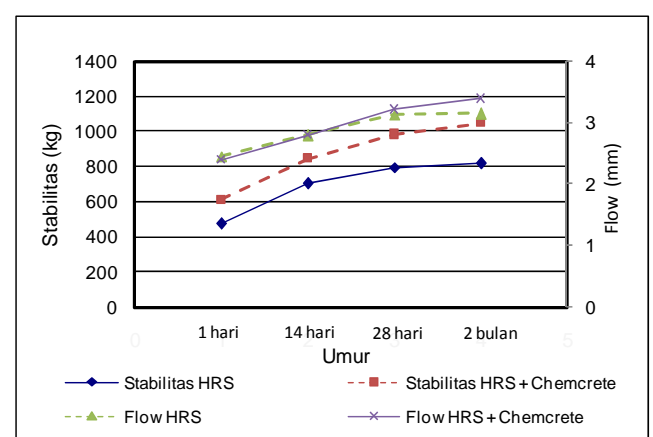

Gambar 7. Grafik Stabilitas Marshall dan Flow HRS dan HRS + Chemcrete vs Waktu

Pada Gambar 7 terlihat dari grafik komposisi campuran HRS dan HRS + Chemcrete dengan vs waktu umur 1 hari, 14 hari, 28 hari, 2 bulan, kadar aspal optimum 6,96\% dari test Marshall II didapatkan HRS + Chemcrete dibanding HRS Stabilitasnya meningkat, diikuti Flow yang masih dalam batas toleransi teknis.

Demikian pula pada Gambar 8 dan Gambar 9 terlihat perbandingan HRS + Chemcrete dan HRS nilai Stabilitas \& Flow yang terjadi juga meningkat pula dengan variasi umur 1 hari, 14 hari, 28 hari, 2 bulan.

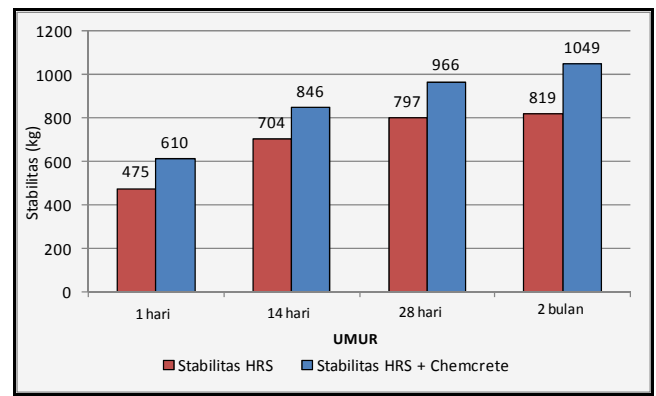

Gambar 8. Grafik Perbandingan Stabilitas HRS dan HRS + Chemcrete vs Waktu 


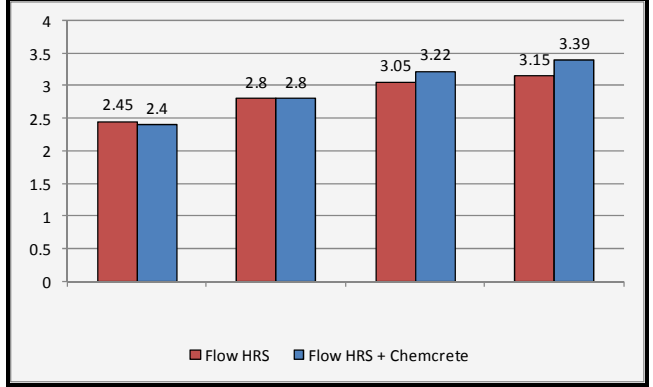

Gambar 9. Grafik Perbandingan Nilai Flow HRS dan HRS + Chemcrete vs Waktu

\section{KESIMPULAN DAN SARAN}

\subsection{Kesimpulan}

Berdasarkan penelitian pengaruh Chemcrete Modifier yang ditambahkan pada campuran HRS terhadap perilaku HRS (stabilitas dan flow) dapat disimpulkan sebagai berikut :

1. Pemakaian HRS sebagai pelapisan perkerasan jalan dari hasil test fisik di laboratorium terhadap Agregat Kasar, Sedang, Halus, Filer dan Aspal mememuhi syarat teknis sesuai hasil Test Marshall I dengan variasi komposisi Aspal 5,5\% $6 \%$ $6,5 \% 7 \% 7,5 \%$ dengan pemadatan $2 \times 75$ pukulan dicapai stabilitas dan flow diatas nilai standar yaitu HRS kelas B (lalu lintas sedang sampai dengan berat $>550 \mathrm{~kg}-1250 \mathrm{~kg}$ ).

2. Dari Campuran HRS dengan kadar Aspal Optimum 6,69\% dari test Marshall II dengan membandingkan HRS dan HRS ditambah Chemcrete dari tabel 7 serta gambar 7 dan 8 dengan variasi umur 1 hari, 14 hari, 28 hari dan 2 bulan didapatkan nilai stabilitas HRS + Chemcrete meningkat dan flow masih dalam batas toleransi, sehingga bisa dipertanggungjawabkan secara teknis, serta kekokohan aspal meningkat, dan akan memperpanjang umur pelayanan perkerasan yang ada.

\subsection{Saran}

1. Dengan terpenuhinya syarat - syarat teknis yang diperlukan, diharapkan akan mampu mereduksi kerusakan kerusakan yang terjadi dan dapat dimanfaatkan dilokasi lain yang memakai HRS sebagai pelapisan permukaan.

2. Sebagai pelapisan permukaan jalan sebaiknya variasi umur ditambahkan sampai 90 hari agar lebih optimal hasilnya.

\section{DAFTAR PUSTAKA}

[1] Petrochemindo Purnama PT, Road Engineering Division, " Chemcrete Modifier High-Strength Modified Asphalt Technology and Products"

[2] Direktorat Bina Marga, 1983 "Petunjuk Pelaksanaan Lapis Tipis Aspal Beton Flexibel (LASTON)", Badan Penerbit Pekerjaan Umum, Jakarta No: 13/ PT/ B/ 1983.

[3] Direktorat Bina Marga, 1983, “ Petunjuk Pelaksanaan Lapis Aspal Beton Fleksibel (LATASTON)", Badan Penerbit Pekerjaan Umum, Jakarta No: 12/ PT/ B/ 1983.

[4] Darmanto, Surisman, Ami Asparini, 1989 " Studi Perbandingan HRS dan HRS memakai Chemcrete ditinjau dari nilai Stabilitas dan Flow sebagai Lapis Permukaan Jalan Gresik - Lamongan Km Sby 16+350 - 17+350", Tugas Akhir LPPU FTSP ITS.

[5] Direktorat Bina Marga, 1976 “ Manual Pemeriksaan Bahan Jalan" Badan Penerbit Departemen Pekerjaan Umum, J akarta.

[6] Colin P. Corne, Specification for High - Durability Asphalts, Maret 1985. Central Design Office Jakarta, Badan Penerbit Pekerj aan Umum. 